Research Articles

\title{
The Effect of Superoxide Dismutase (SOD) Supplementation Towards Plasma Levels of Malondialdehyde (MDA), Total Cholesterol and LDL Cholesterol in the Elderly
}

\author{
Dwi Ngestiningsih ${ }^{1,2}$, Rejeki Andayani Rahayu², Lusiana Batubara ${ }^{1}$ \\ ${ }^{1}$ Department of Medical Biology and Biochemistry, Faculty of Medicine, Diponegoro University, Semarang, \\ Indonesia \\ ${ }^{2}$ Department of Internal Medicine, Faculty of Medicine, Diponegoro University, Semarang, Indonesia
}

Article Info
History
Received : 13 March 2019
Accepted : 10 Oct 2019
Available : 31 Dec 2019

Available : 31 Dec 2019

\begin{abstract}
Background: Several various physiological functions in elderly people are diminished due to cell or tissue damage. One of the probable causes is oxidative stress yielded by free radicals. Oxidative stress (ROS) induce lipid peroxidation in the endothelial cell membrane, which generates atherosclerotic plaque. In a state of oxidative stress, the MDA level will increase. The purpose of this study is to determine the effect of SOD supplementation towards MDA, total cholesterol and LDL cholesterol plasma levels in the elderly.

Methods: This study was an open-label randomized control trial. Subjects were elders people aged $>60$ years institutionalized at Social Rehabilitation Unit Pucang Gading Semarang, Indonesia. The treatment group consisted of 16 people, received SOD (Glisodin ${ }^{\circledR}$ ) 1 capsule (250 IU) 1 hour before meals and daily elderly exercise (senam lansia) scheduled for 8 weeks. The control group consisted of 15 people, received a placebo, and daily elderly exercise. Plasma MDA levels were examined using TBARS method, while total cholesterol and LDL cholesterol were examined using CHODPAP method.

Results: This study shows a trend of reduction of plasma MDA levels in the treatment group compared to the control group $(\mathrm{p}=0.062)$. A significant reduction of total cholesterol and LDL cholesterol levels in the treatment group were found (before 190.00 and $131.47 \mathrm{~g} / \mathrm{dl}$, after 182.27 and $121.93 \mathrm{~g} / \mathrm{dl}, \mathrm{p}=0.005$ and 0.001 ).

Conclusion: The SOD supplementation significantly reduces Total Cholesterol and LDL level, but not MDA level in the elderly.
\end{abstract}

Keywords: SOD; MDA; Total Cholesterol; LDL Cholesterol Permalink/ DOI: https://doi.org/10.14710/jbtr.v5i2.4679

\section{INTRODUCTION}

Several various physiological functions in elderly people are diminished due to cell or tissue damage. Cellular damage accumulated over the years along with increasing age, resulted in many degenerative diseases. ${ }^{(1)}$ One of the probable causes is oxidative stress yielded by free radicals. Free radicals are highly reactive, causing biochemical changes and damages in various components of living cells, such as proteins, lipids, carbohydrates and nucleic acids.

\footnotetext{
* Corresponding author:

E-mail: tj.batubara@gmail.com (Lusiana Batubara)
}

Free radical attacks against lipid component in the cell membrane will cause lipid peroxidation reaction, producing toxic substances to the cells such as malondialdehyde (MDA). ${ }^{(1,2)}$ Malondialdehyde (MDA) is one of the compound products of lipid peroxidation reaction used as a marker for oxidative stress state. In a state of oxidative stress, MDA serum levels will increase significantly. ${ }^{(3)}$

Reactive Oxygen Species (ROS) can induce lipid peroxidation in the cell wall, including endothelial cells, thus causing injury to these cells (endothelial injury). Injured endothelial cells are marked by increased NO response, followed by an immunologic response. In 
addition, the continuous mild ROS can accelerate senescence cells. Constantly, this process will shorten endothelial cell telomeres while triggering the emergence of Advanced Glycation End (AGE) products. AGE accumulated by the age will activate $\mathrm{NAD}(\mathrm{P}) \mathrm{H}$ oxidase which will increase the production of superoxide anion while activating monocytes into macrophages. This process continues and finally induces endothelial dysfunction that leads to thrombosis. ${ }^{(4)} \mathrm{NAD}(\mathrm{P}) \mathrm{H}$ oxidases are not increased due to aging only, but also it occurs in the pathophysiologic state causing cardiovascular diseases such as hypercholesterolemia, hypertension and diabetes. ${ }^{(5)}$ Macrophages and fat, especially low-density lipoprotein (LDL), accumulate in the area of injury where LDL is oxidized and eaten by macrophages or the macrophages themselves are also oxidized to produce foam cells, which can develop into atherosclerotic plaques. ${ }^{(4)}$

Lipid peroxide is formed from the process of lipid peroxidation due to the attack by free radicals. Biological membranes and lipoproteins are sensitive to lipid peroxide. It will decrease the stability of the cell membrane, inducing oxidation of the thiol groups by the enzyme in the membrane and releasing product breakdown (such as malondialdehyde [MDA]) which will cause cell damage. LDL oxidation by free radicals can cause tissue damage in blood vessels. ${ }^{(6)}$

SOD is one of the antioxidant enzymes which catalyze dismutase reactions or disproportionation of superoxide into molecular oxygen and peroxide. Peroxide then undergoes catalytic reaction into water molecules by catalase and peroxidase. SOD plays an important role in protecting cells from toxic products resulted from the process of aerobic metabolism, and oxidative phosphorylation. ${ }^{(7)}$

Antioxidant supplementation has been used often by Western people. Many supplements have been developed over several years. Studies have been conducted and data were collected from the animal experiments to clinical studies. ${ }^{(8)}$

Since 2000, the melon extract with naturally fortified SOD has been developed as a food supplement. Due to the low $\mathrm{pH}$ and high proteolytic activity in the digestive system, however, the SOD will undergo structural changes and will become inactive, thus a single administration of SOD is considered less effective. At present, the compound used for SOD coating processes that are often studied is gliadin, which is produced from wheat. Some studies claim that wheat gliadin protects the SOD from degradation process in the stomach. ${ }^{(8)}$

Based on the previous studies, consumption of SOD supplements may provide a beneficial effect towards the diseases triggered by oxidative stress such as cardiovascular disease, cancer and infections, such as Feline Immunodeficiency Virus (FIV) that is homologous with Human Immunodeficiency Virus (HIV) virus. SOD oral supplementation may also indicate a significant increase in quality of life. ${ }^{(9)}$

Plasma cholesterol, especially the oxidized cholesterol, contributes to generate free radicals on the endothelial cells of blood vessel walls. LDL oxidized into OxLDL stimulates the formation of superoxide anion $\left(\mathrm{O}_{2}^{--}\right)$causing cell wall apoptosis in the vascular. ${ }^{(10,11)}$
Based on the above explanation, this study aims to compare the plasma MDA levels, total plasma cholesterol levels and plasma LDL cholesterol levels in the SOD group compared to the control group/placebo.

\section{METHODS \\ Research design}

This study was an open-label randomized control trial of experimental research.

\section{Study subjects}

Subjects for this study were elders aged $>60$ years institutionalized at Social Rehabilitation Unit Pucang Gading Semarang. Physically healthy, able to perform activities of daily life (ADLs) independently based on the Barthel index, able to communicate, willing to participate in the study and signed informed consent.

From a total of 115 elderly populations in the orphanage, there were 31 people who met the inclusion criteria. From samples that met the inclusion criteria, measurements of weight, height, Body Mass Index (BMI) and blood pressure were conducted.

\section{Intervention}

Thirty-one persons who met the inclusion criteria were randomly divided into two groups: treatment group $(\mathrm{n}=16)$ which was administered with SOD supplementation $\left(\right.$ Glisodin $\left.^{\mathrm{R}}\right)$ and control group $(\mathrm{n}=15)$ which was administered with placebo. Both groups received their relevant treatment one capsule daily, one hour before breakfast for 8 weeks and given daily elderly exercise (senam lansia) for 0.5 - 1 hour.

\section{Laboratory analysis}

Plasma MDA levels were measured by using Thiobarbituric Acid Reactive Substances (TBARS) method at the Biochemistry laboratory, Faculty of Medicine Diponegoro University. Total plasma cholesterol levels and plasma LDL cholesterol levels were determined by using Cholesterol Oxidase Peroxsidase Aminoantypirin (CHOD-PAP) enzymatic methods in CITO clinical laboratory Semarang.

\section{Statistical analysis}

Data analysis was performed using Shappiro-Wilk test and paired t-test with SPSS software version 20.0. p value $<0.05$ was considered as significant.

\section{Ethical clearance}

This study was approved by medical research ethics committee (KEPK) Faculty of Medicine Diponegoro University Semarang

\section{RESULTS}

A total of 31 subjects with mean $( \pm$ SD) age $71.42( \pm 6.2)$ years were recruited for this study. Baseline characteristics of the study population were presented in table 1 . 
Table 1. Baseline characteristics of study population

\begin{tabular}{lccc}
\multicolumn{1}{c}{ Variable } & $\begin{array}{c}\text { Treatment group } \\
(\mathrm{n}=16)\end{array}$ & $\begin{array}{c}\text { Control group } \\
(\mathrm{n}=15)\end{array}$ & $\begin{array}{c}\text { Total } \\
(\mathrm{n}=31)\end{array}$ \\
\hline Age $($ years $)$ & $6(37.5 \%)$ & $5(33.3 \%)$ & $11(35.5 \%)$ \\
$60-69$ & $8(50 \%)$ & $10(66.7 \%)$ & $18(58.1 \%)$ \\
$70-79$ & $2(12.5 \%)$ & - & $2(6.5 \%)$ \\
$80-89$ & $3(18.8 \%)$ & $7(46.7 \%)$ & $10(32.3 \%)$ \\
Gender & $13(81.3 \%)$ & $8(53.3 \%)$ & $21(67.7 \%)$ \\
$\quad \begin{array}{l}\text { Male } \\
\text { Female }\end{array}$ & $15(93.8 \%)$ & $12(80 \%)$ & $27(87.1 \%)$ \\
BMI groups & $1(6.3 \%)$ & $3(20 \%)$ & $4(12.9 \%)$ \\
$\quad \begin{array}{l}\text { Under/normal weight } \\
\text { (BMI <25) }\end{array}$ & & & \\
$\begin{array}{l}\text { Overweight/obese } \\
\text { (BMI } \geq 25)\end{array}$ & $10(62.5 \%)$ & $5(33.3 \%)$ & $15(48.4 \%)$ \\
Blood pressure & $6(37.5)$ & $10(66.7 \%)$ & $16(51.6 \%)$ \\
$\quad \begin{array}{l}\text { Hipertension } \\
\text { Normal }\end{array}$ & & &
\end{tabular}

BMI, Body Mass Index

In the treatment group (given SOD for 8 weeks) there was a trend of decrease in plasma MDA levels, but it was not significant (table 2). The differences between treatment and control group were not differently significant.
Increased plasma MDA levels may have resulted from continuous exposure to free radicals continuously, such as free radicals in metabolism products, chronic inflammation, and cigarette smoke. Aging process has similar characteristic with mild chronic inflammation

Table 2. Table 1. Mean MDA level (ngr/dl) in treatment and control groups

\begin{tabular}{lccccc}
\hline & Before $(\mathbf{n g r} / \mathbf{d l})$ & After $(\mathbf{n g r} / \mathbf{d l})$ & $\mathbf{p}^{*}$ & $\boldsymbol{\delta}$ & $\mathbf{p}^{* *}$ \\
\hline Treatment & $13.44 \pm 1.30$ & $12.63 \pm .94$ & .062 & .81 & 0.59 \\
Control & $13.05 \pm 1.57$ & $13.08 \pm .95$ & .968 & .03 & \\
\hline
\end{tabular}

*paired t-test

$* *$ independent t-test

There was a decrease in plasma cholesterol levels after administration of SOD for 8 weeks. After being analyzed the decline was significant ( $p$ value 0.005 ). However the differences between treatment and control group were not statistically significant (table 3).

There was a decrease in plasma LDL Cholesterol levels after administration of SOD for 8 weeks (table 4). After being analyzed the decline was significant ( $\mathrm{p}$ value 0.005). However the differences between treatment and control group were not statistically significant. increase MDA levels. Cigarette smoke also can increase lipid peroxidation which in turn increase the levels of plasma MDA. ${ }^{(2,6,12)}$

Bose et al. found that by administering of tomatoes for 45 days, there was an increase in the levels of antioxidant enzymes (superoxidedismutase (SOD), glutathione peroxidase (GSH-Px), glutathionereductase (GR), reduced glutathione (GSH)) and decreased levels of lipid peroxidation (measured by the levels of plasma malondialdehyde (MDA)). One important role of the

Table 3. Mean Total Cholesterol level (gr/dl) in treatment and control group

\begin{tabular}{lccccc} 
& Before $(\mathbf{g r} / \mathbf{d l})$ & After $(\mathbf{g r} / \mathbf{d l})$ & $\mathbf{p}^{*}$ & $\boldsymbol{\delta}$ & $\mathbf{p}^{* *}$ \\
\hline Treatment & $190.00 \pm 42.86$ & $182.27 \pm 46.41$ & $\mathbf{. 0 0 5}$ & 7.73 & 0.42 \\
Control & $218.13 \pm 50.29$ & $226.13 \pm 74.40$ & .503 & 8 & \\
\hline
\end{tabular}

*paired t-test: significant $\mathrm{p}$ value is bolded

**independent $\mathrm{t}$-test

\section{DISCUSSION}

This study found a trend of reduction of plasma MDA levels in the treatment group, although it was not statistically significant. Reduction in plasma cholesterol levels, total cholesterol and LDL cholesterol levels, were also found after SOD administration for 8 weeks and it was statistically significant (p value of 0.005 and 0.001 ). No reduction was found in neither plasma cholesterol levels, total cholesterol nor LDL cholesterol levels, in the control group despite the exercise prescription. intracellular antioxidant is as a free radical scavenger by changing harmful superoxide ions into stable hydrogen peroxide. In the oxidative stress state, all biomedical substances may be attacked by free radicals, but lipids are more vulnerable. Human cells are rich sources of polyunsaturated fatty acids (PUFAs), so it can be easily attacked by free radicals by a process known as lipid peroxidation to form lipid peroxides. This is a continuous chain reaction that is very destructive. ${ }^{(13,14)}$ 
Table 4. Mean LDL Cholesterol level (gr/dl) in treatment and control group.

\begin{tabular}{lccccc} 
& Before $(\mathrm{gr} / \mathrm{dl})$ & After(gr/dl) & $\mathbf{p}^{*}$ & $\boldsymbol{\delta}$ & $\mathbf{p}^{* *}$ \\
\hline Treatment & $131.47 \pm 35.80$ & $121.93 \pm 33.11$ & .001 & 9.54 & 0.99 \\
Control & $149.75 \pm 44.43$ & $148.88 \pm 57.05$ & .934 & .87 & \\
\hline
\end{tabular}

*paired t-test: significant p value is bolded

**independent t-test

In this study, SOD supplementation caused a slight trend of decrease in levels of plasma MDA, but it was not statistically significant. This could occur due to the volatile MDA so if is not examined immediately after sampling, the actual levels of MDA would have changed. Moreover, it could be caused by a small number of samples included in this study.

After SOD supplementation for 8 weeks, there were changes in total plasma cholesterol levels in both groups in comparison with pre-treatment levels. But no difference was found between SOD and control group. The sample of this study were institutionalized at Social Rehabilitation Unit Pucang Gading Semarang, were given the same amount and types of food and did routine elderly exercise every morning.

Oliveras-Lópezetal found that there were significant improvements in lipid profiles, including a decrease in total cholesterol levels and an increase in HDL levels after daily consumption of virgin olive oil daily for 6 weeks in 62 people aged 65-96 years. Park and Kim reported that triglyceride levels, total plasma cholesterol and plasma LDL cholesterol in Korean elders decreased significantly after the administration of Spirulina (a cyanobacterium/blue-green algae, which serves as a food supplement that contains essential fatty acids, vitamin $\mathrm{B}$, iron, manganese). Pourghassem-Gargari et al. (2009) reported that the administration of Nigella sativa/cumin in hyperlipidemic rabbits can lower total cholesterol, triglycerides and LDL cholesterol and lipid peroxide (MDA) levels significantly $(p<0.05)$. Hasan et al. (2011) suggested that $U$. lactuca (green algae) extract intra gastric in hypercholesterolemic rats caused a decrease in total serum lipids, triglycerides, total cholesterol, LDL cholesterol and VLDL cholesterol where the levels of HDL-cholesterol clearly increased by approximately $180 \% .^{(17-19)}$

This is in line with the research theory by Paolo Mondola stating that $\mathrm{Cu}, \mathrm{Zn}$-SOD inhibits the activity of $\mathrm{HMG}$ Co-A reductase in the liver cells of rats. HMG CoA reductase is an enzyme that plays an important role in the biosynthesis of cholesterol and other large molecules through the production of mevalonic acid pathway. $\mathrm{Cu}$, Zn-SOD inhibits HMG Co-A reductase by binding to the hepatocyte cells and undergoes internalization by absorptive endocytosis. Inhibitory effect of $\mathrm{Cu}, \mathrm{Zn}-\mathrm{SOD}$ is mediated by phospholipid membrane pathways that are activated by the bond between the receptor and the membrane of $\mathrm{Cu}, \mathrm{Zn}$-SOD surface. Inhibition of HMG Co-A reductase will lead to reduced cholesterol synthesis. Inhibition of cholesterol synthesis will lead to activation of LDL Receptor Pathway accompanied by an increasing amount of LDL cholesterol which binds to a receptor of hepatocyte cell surface, thereby lowering LDL cholesterol in blood. LDL cholesterol is a major lipoprotein of cholesterol carrier in the body and becomes an important independent risk factor in the formation of atherosclerosis. ${ }^{(20)}$ On aging, there is also an increased risk of atherosclerosis in relation with the increased fatty streak in the intima layer of blood vessels. ${ }^{(20)(21)(22)}$

In this research we found that SOD supplementation is beneficial in lowering serum LDL levels and we did not find any complaint from the subject during and after the treatment. We found there was no side-effect of SOD supplementation for the elderly, so that SOD supplementation is safe to use for the elderly. ${ }^{(23)(24)}$

Our study limitation is the lack data on food intake history and exercise compliance. Food intake from all of the residents was controlled by nursing personnel every day, however the compliance was still low.

\section{CONCLUSION}

In this study, Glisodin ${ }^{\circledR}$ supplementation reduced Total Cholesterol and LDL level, but not MDA level in the elderly. Further research needs to be done on SOD supplementation in the elderly with a longer period time and a larger number of samples so it can be known whether the SOD can be used as a supplementation for statins in reducing total plasma cholesterol and plasma LDL cholesterol levels. However further research on the effects of SOD supplementation on the lipid profile, such as triglycerides and plasma HDL, requires carrying out at long-term in an effort to determine the effects of the prevention of cardiovascular disease. Its effect towards the cognitive status in the elderly is also required.

\section{REFERENCES}

1. Hekimi S, Lapointe J, Yang Wen. Taking a "good" look at free radicals in the aging process. Trends Cell Biol 2011 Oct; 21(10): 569-576. https://doi: 10.1016/j.tcb.2011.06.008

2. Balaban RS, Nemoto S, Finkel T. Mitochondria, oxidants, and aging. Cell 2005;120(4):483-95. https://doi.org/10.1016/j.cell.2005.02.001

3. Ayala A, Muñoz M, Argüelles S. Lipid Peroxidation: Production, Metabolism, and Signaling Mechanisms of Malondialdehyde and 4-Hydroxy-2-Nonenal. Oxidative Med Cell 2014.

http://dx.doi.org/10.1155/2014/360438

4. Mudau M, Genis A, Lochner A, Strijdom H. Endothelial dysfunction: the early predictor of atherosclerosis. Cardiovasc J Afr 2012;23(4):222-31. https://www.ncbi.nlm.nih.gov/pmc/articles/PMC372 $1957 /$

5. Csiszar A, Ungvari Z, Edwards JG, Kaminski P, Wolin MS, Koller A, et al. Aging-induced phenotypic changes and oxidative stress impair coronary arteriolar function. Circ Res 2002;90(11):1159-66. https://doi.org/10.1161/01.RES.0000020401.61826. EA

6. Colak E. Review article: New markers of oxidative damage to macromolecules. JMB 27: 1-16, 2008. DOI: $10.2478 / \mathrm{v} 10011-007-0049$ 
7. Perry JJP, Shin DS, Getzoff ED, Tainer JA. The structural biochemistry of the superoxide dismutases. Biochim Biophys Acta - Proteins Proteomics. Elsevier B.V. 2010;1804(2):245-62. https://doi.org/10.1016/j.bbapap.2009.11.004

8. Nakajima S, Ohsawa I, Nagata K, Ohta S, Ohno M, Ijichi $\mathrm{T}$, et al. Oral supplementation with melon superoxide dismutase extract promotes antioxidant defences in the brain and prevents stress-induced impairment of spatial memory. Behav Brain Res. Elsevier B.V. 2009;200:15-21. https://doi.org/10.1016/j.bbr.2008.12.038

9. Romao S. Therapeutic value of oral supplementation with melon superoxide dismutase and wheat gliadin combination. Nutrition [Internet]. Elsevier Inc 2015;31(3):430-6. http://dx.doi.org/10.1016/j.nut.2014.10.006

10. $\mathrm{Xu} \mathrm{L,} \mathrm{Porter} \mathrm{NA.} \mathrm{Free} \mathrm{radical} \mathrm{oxidation} \mathrm{of}$ cholesterol and its precursors: Implications in cholesterol biosynthesis disorders. Free Radic Res 2015;49(7):835-49.

DOI: $10.3109 / 10715762.2014 .985219$

11.Cominacini L, Rigoni A, Pasini AF, Garbin U, Davoli A, Campagnola M, et al. The Binding of Oxidized Low Density Lipoprotein (ox-LDL) to ox-LDL Receptor-1 Reduces the Intracellular Concentration of Nitric Oxide in Endothelial Cells through an Increased Production of Superoxide. J Biol Chem 2001;276(17):13750-5. doi: 10.1074/jbc.M010612200

12. Ho E, Galougahi KK, Chia-Chi Liu,Bhindi R, Figtree A. Review Article: Biological markers of oxidative stress: Applications to cardiovascularresearch and practice. Redox Biology 1 2013; 483-491 doi: 10.1016/j.redox.2013.07.006.

13.Bose KSC, Agrawal BK. Effect of Long Term Supplementation of Tomatoes (Cooked) on Levels of Antioxidant Enzymes, Lipid Peroxidation Rate, Lipid Profile and Glycated Haemoglobin in Type 2 Diabetes Mellitus 2006;55(4):274-8.

http://caribbean.scielo.org/pdf/wimj/v55n4/a10v55n 4.pdf

14.Rajprabha, Hamid, Kumarmeena R, Syedyawer H. Study of Antioxidant Enzyme -Superoxide Dismutase Activity and Lipid Profile in Diabetes Mellitus patients. Int $\mathbf{J}$ Healthc Biomed Res 2014;2(4):22-9. http://ijhbr.com/pdf/22-29.pdf

15. Décordé K, Ventura E, Lacan D, Ramos J, Cristol JP, Rouanet JM. An SOD rich melon extract Extramel囚prevents aortic lipids and liver steatosis in diet-induced model of atherosclerosis. Nutr Metab Cardiovasc Dis 2010;20(5):301-7. doi:10.1016/j.numecd.2009.04.017

16.Carillon J, Rouanet JM, Cristol JP, Brion R. Superoxide dismutase administration, a potential therapy against oxidative stress related diseases: Several routes of supplementation and proposal of an original mechanism of action. Pharm Res 2013;30(11):2718-28.

DOI 10.1007/s11095-013-1113-5
17. Oliveras-López MJ, Molina JJM, Mir MV, Rey EF, Martín F, De la Serrana HLG. Extra virgin olive oil (EVOO) consumption and antioxidant status in healthy institutionalized elderly humans. Arch Gerontol Geriatr 2013;57(2):234-42.

http://dx.doi.org/10.1016/j.archger.2013.04.002

18. Pourghassem-Gargari B, Ebrahimzadeh-Attary V, Rafraf M, Gorbani A. Effect of dietary supplementation with Nigella sativa L. on serum lipid profile, lipid peroxidation and antioxidant defense system in hyperlipidemic rabbits. J Med Plants Res 2009;3(10):815-21.

http://www.academicjournals.org/JMPR

19. Hassan S, El-Twab SA, Hetta M, Mahmoud B. Improvement of lipid profile and antioxidant of hypercholesterolemic albino rats by polysaccharides extracted from the green alga Ulva lactuca Linnaeus. Saudi J Biol Sci [Internet]. King Saud University 2011;18(4):333-40.

http://dx.doi.org/10.1016/j.sjbs.2011.01.005

20. Mondola P, Damiano S, Sasso A, Santillo M. The Cu, $\mathrm{Zn}$ superoxide dismutase: Not only a dismutase enzyme. Front Physiol 2016;7(NOV):1-8. doi: 10.3389/fphys.2016.00594

21. Zou Y, Corniola R, Leu D, Khan A, Sahbaie P, Chakraborti A, et al. Extracellular superoxide dismutase is important for hippocampal neurogenesis and preservation of cognitive functions after irradiation. Proc Natl Acad Sci USA 2012;109(52):21522-7.

https://www.ncbi.nlm.nih.gov/pmc/articles/PMC353 5634/pdf/pnas.201216913.pdf

22. Fattman CL, Schaefer LM, Oury TD. Extracellular superoxide dismutase in biology and medicine. Free Radic Biol Med 2003;35(3):236-56. doi:10.1016/S0891-5849(03)00275-2

23. Cloarec M, Caillard P, Provost JC, Dever JM, Elbeze Y, Zamaria N. GliSODin, a vegetal sod with gliadin, as preventative agent vs. atherosclerosis, as confirmed with carotid ultrasound-B imaging. Eur Ann Allergy Clin Immunol 2007;39(2):45-50. https://pdfs.semanticscholar.org/0321/1303683c8ff7 64923e0dd49651c530165501.pdf

24. Skarpanska-Stejnborn A, Pilaczynska-Szczesniak L, Basta P, Deskur-Smielecka E, Woitas-Slubowska D, Adach Z. Effects of oral supplementation with plant superoxide dismutase extract on selected redox parameters and an inflammatory marker in a 2,000-m rowing-ergometer test. Int J Sport Nutr Exerc Metab 2011;21(2):124-34.

http://www.glisodin.org/wpcontent/uploads/2015/04/glisodin-sport-in-int-jsport-nutr-exerc-metab.pdf 